\title{
Wear of the Primary WaveOne single file when shaping vestibular root canals of first maxillary molar
}

\author{
Daniel Aracena ${ }^{1}$, Eduardo Borie ${ }^{2}$, Pablo Betancourt ${ }^{3}$, Angella Aracena ${ }^{4}$, Mario Guzmán ${ }^{5}$ \\ ${ }^{1}$ MSc, Dental School, Universidad Mayor, Temuco, Chile \\ ${ }^{2} \mathrm{PhD}$, Research Centre in Dental Sciences (CICO), Dental School, Universidad de La Frontera, Temuco, Chile \\ ${ }^{3} \mathrm{MSc}$, Universidad de La Frontera, Temuco, Chile \\ ${ }^{4}$ Prof, Universidad Autónoma de Chile, Chile \\ ${ }^{5} \mathrm{PhD}$, Mechanical Engineering Department, Universidad de La Frontera, Temuco, Chile
}

Correspondence:

Av. Alemania 0281, Postal code: 4801043

Phone number: 56-45-2206206

Dental School, Universidad Mayor, Teтисо - Chile

draracena@gmail.com

Received: 25/07/2016

Accepted: 17/11/2016

Aracena D, Borie E, Betancourt P, Aracena A, Guzmán M. Wear of the Primary WaveOne single file when shaping vestibular root canals of first maxillary molar. J Clin Exp Dent. 2017;9(3):e368-71.

http://www.medicinaoral.com/odo/volumenes/v9i3/jcedv9i3p368.pdf

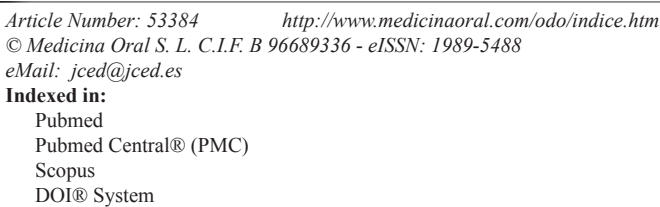

\begin{abstract}
Background: It is very important for a clinician to know the increased wear of mechanized files when establishing endodontic therapy. The aim of this study was to check the wear of the Primary WaveOne file upon shaping two, four and six maxillary molar vestibular canals.

Material and Methods: The deterioration of 40 files, divided into four groups, was evaluated microscopically: group 1, control (unused); group 2, two canals; group 3, four canals; and group 4, six canals. After instrumentation, the files were embedded in resin and sectioned at their apical third into three equal parts. To analyze the wear of edges in the different sections, AutoCAD software was used and analysis of variance (ANOVA) was then performed to compare the mean rake angles.

Results: The files with two and four uses showed slight wear, whereas those with six applications showed significant wear $(p<0.05)$.

Conclusions: Primary WaveOne files can be used in up to four root canals without their edges losing effectiveness.
\end{abstract}

Key words: Files wear, reciprocating motion, shaping capacity, WaveOne.

\section{Introduction}

Correct shaping of the canal is essential for the effectiveness of some stages of endodontic treatment, such as chemical disinfection and root filling $(1,2)$.

In recent decades, nickel-titanium (NiTi) alloy, introduced to the field of endodontics in 1988, has become the most widely used memory alloy, as it has a wide range of biomedical applications due to its superelasticity and its capacity to recover its original shape after undergoing great deformations $(3,4)$. With respect to mechanized techniques, this alloy has facilitated the instrumentation of curved root canals with rotational techniques, improving 
outcome quality in addition to reducing working time and the physical effort of the operator compared with manual techniques $(5,6)$.

Despite the considerable improvements in NiTi instrument design, manufacturing methods and rotary shaping techniques, fractures of files in canals with severe curves still occur (7). Fatigue failure generally occurs due to the formation of microcracks in the surface of the instrument. During each load cycle, microfissures develop from surface irregularities, and these subsequently expand through the material until the instrument completely separates (8). To address this type of accident, optimization of the microstructure of the alloy through new processing technologies has been proposed. Recently, a new NiTi material called M-Wire has been developed through a thermo-mechanical process and shows considerable improvement in resistance to cyclic fatigue compared with conventional NiTi (9-11).

Existing techniques for reciprocating canalicular shaping using a single M-Wire instrument aim to simplify the instrumentation process, to avoid the risk of crosscontamination and to increase resistance to cyclic fatigue (12). One such reciprocating system is the WaveOne (Dentsply-Maillefer ${ }^{\circledR}$, Ballaigues, Switzerland), whose working angles are $50^{\circ}$ clockwise and $170^{\circ}$ counterclockwise (13). The advantages of this reciprocating motion are based on the physical laws of action and reaction applied to instrumentation of the canal, which result in a balanced force (14).

At present, there is no available information on the wear that can occur on the single file of the WaveOne system as it is used. The aim of this study was to test in vitro the degree of wear experienced by the Primary file of the WaveOne reciprocating system upon instrumenting 2, 4 and 6 maxillary molar root canals. The null hypothesis was that the primary file of the WaveOne reciprocating system has no significant wear of its edges upon instrumenting two, four and six root canals.

\section{Material and Methods}

This study was approved by the Ethics Committee of the University of La Frontera, Temuco, Chile (DI 16/ 0048).

This study conducted a microscopic evaluation of the deterioration of the edges of 40 Primary single-use 25/0.8 files of the WaveOne reciprocating system (DentsplyMaillefer ${ }^{\circledR}$, Ballaigues, Switzerland), which were divided into four groups ( $\mathrm{n}=10$ each group). Group 1, or control, corresponded to unused files; group 2 corresponded to files with two instrumented canals; group 3 corresponded to files with four instrumented canals; and group 4 corresponded to files with six instrumented canals.

Between groups 2, 3 and 4, 120 root canals in total were shaped from primary human molars and maxilla extracted from caries and/or periodontal disease. Teeth that were included at random in different groups were selected according to the following criteria: mature apexes, canalicular curvatures equal to or less than 34 degrees, canals with independent foramina, no calcification and no reabsorptions.

The molars were subject to the following protocol: once extracted, they were submerged in a solution of $5.25 \%$ sodium hypochlorite $(\mathrm{NaOCl})$ for 20 minutes for disinfection and removal of organic residues. After washing with water, any caries and residual and hydrated restorations were removed from samples, which were then maintained in $2 \%$ chlorhexidine solution. Access to the cavity was initially prepared with a high-speed 801L round diamond bur (Jota $\AA$, Rüthi, Switzerland) and was then finished by removing all of the chamber roof with an Endozeta bur (Dentsply-Maillefer ${ }^{\circledR}$, Ballaigues, Switzerland), both cooled with air-water spray. After accessing the canals, the working length was established, subtracting $1 \mathrm{~mm}$ of the length of a $\mathrm{K} 10$ file, after visualizing emergence in the apical foramen.

Next, radiographic images were taken of each of the samples with $70 \mathrm{kV}$ equipment (Soredex, Tuusula, Finland) and periapical radiographic film (Ultra Speed, DF58, Kodak ${ }^{\circledR}$, Rochester, NY, USA) using a work table that allowed standardizing the technique by positioning teeth at a distance of $47.2 \mathrm{~cm}$. The image plates were processed in an automatic developer (Perio Mat Plus, Dürr Dental AG, Bietigheim-Bissingen, Germany), and the images obtained were photographed and processed according to the Schneider technique (15). The AutoCAD 2015 program was used to trace and determine the angulation of root canals. Each of the samples was subsequently mounted in a plaster block to continue with the in vitro instrumentation.

According to the manufacturer's indication, after scouting the canals with a K 10 file (Dentsply-Maillefer ${ }^{\circledR}$, Ballaigues, Switzerland), a Primary 25.08 mechanized file of the WaveOne reciprocating system was selected, with which an experienced operator proceeded to instrument the vestibular canals of the sample, using a specific reciprocating motion of 170 counter-clockwise (CCW) and 50 clockwise $(\mathrm{CW})$ and a speed of $350 \mathrm{rpm}$.

For irrigation, 5\% sodium hypochlorite solution was used, and canals were scouted with a K 10 file, with a 2-mm progression into the canal each time the file was applied. An X-Smart Plus motor (Dentsply-Maillefer ${ }^{\circledR}$, Ballaigues, Switzerland) was used in the shaping of canals with a program indicated for WaveOne system files according to the manufacturer's instructions.

All of the files used were subjected to sterilization via ethylene oxide to prevent deterioration of the silicone safety installed in the handle.

-Embedding endodontic files

After shaping the respective canals, primary files were embedded inside cylindrical molds filled with vinylester 
A-430 resin (BASF®, Concón, Chile), which uses cobalt and standard methyl ethyl ketone peroxide as catalysts, both at a ratio of $0.2 \mathrm{ml}$ per $100 \mathrm{ml}$ of resin.

-Sectioning of the files

The files were sectioned using an EZ lock diamond disc (Dremel®, México DF, Mexico). The apical third of the files was then divided into three equal parts: the first section $(\mathrm{C} 1)$ was made $1.88 \mathrm{~mm}$ from the tip, and after obtaining the corresponding image, the second section (C2) was made at the same distance, to finally make the third section (C3) (Fig. 1). Lastly, the samples were subjected to unidirectional fine grinding for microscopic analysis.

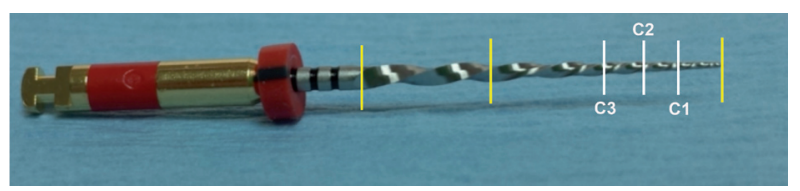

Fig. 1. Primary file showing the three sections analyzed (C1, $\mathrm{C} 2$ and C3).

-Measurement of rake angles of the file

A specific platform was built to obtain standardized images of the files. For this procedure, a mobile device was used on which the file was always placed in the same position and at the same distance from the microscope. These images were obtained using a Moticam 5 camera (Motic ${ }^{\circledR}$, Hong Kong, China) coupled to a stereoscopic microscope (Motic ${ }^{\circledR}$ model SMZ 168, MoticXiamen, Fujiam, China) with a direct USB connection to a computer. Images were then analyzed with the program AutoCAD ${ }^{\circledR} 2015$ (Autodesk ${ }^{\circledR}$, California, CA, USA), determining corresponding cross-sections to the cuts $\mathrm{C} 1$, $\mathrm{C} 2$ and $\mathrm{C} 3$ to then proceeding to measure rake angles in each section after the files shaped zero, two, four and six canals.

-Statistical analysis

Statistical analysis was performed with SPSS v. 16.0 (SPSS Inc., Chicago, IL, USA) with a significance level of $95 \%$. The frequency distribution analysis of the samples (Shapiro-Wilk test) and the homogeneity of variance test (Levene test) revealed that the samples were normal and homogenous, indicating the use of parametric tests. For comparison of rake angles of the files between different sections and uses, analysis of variance (ANOVA) with Bonferroni correction was used.

\section{Results}

The variations of average rake angles of the Primary files in relation to the numbers of uses and sections are summarized in table 1 .

Files used for shaping two, four and six root canals showed negative linear progressive increases in rake angles, causing decreases in the cutting actions of the instrument edges (Fig. 2); however, significant differences were only observed between unused files and files that shaped six canals.

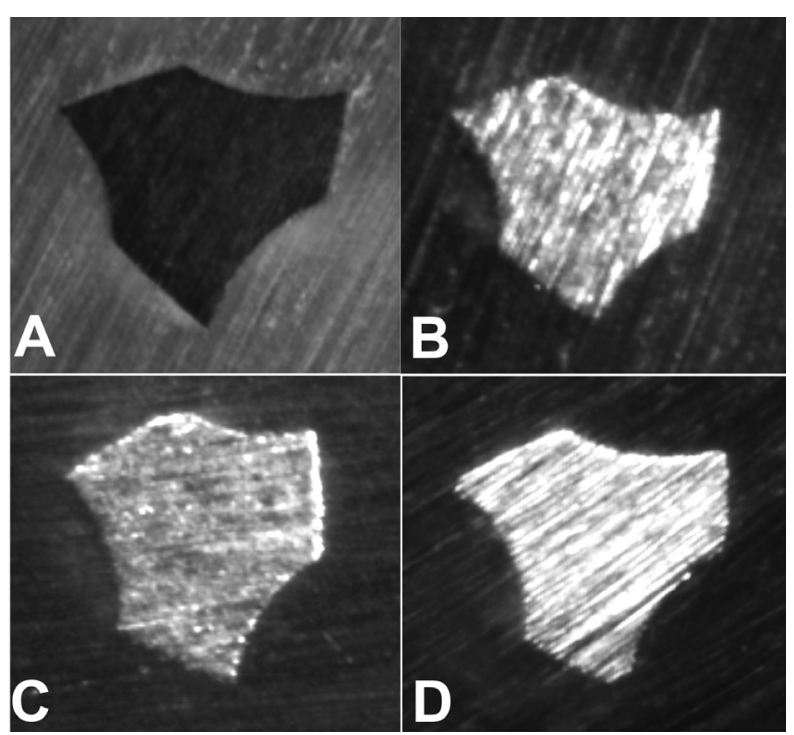

Fig. 2. Stereomicroscopic view of the wear of the edges of the Primary files. A) Unused file; B) Used in two canals; C) Used in four canals; D) Used in six canals.

\section{Discussion}

All endodontic files have surface irregularities and internal defects resulting from the manufacturing process, a situation that influences the instrument's resistance to fracture (16). Accordingly, a large percentage of new Primary files showed various irregularities in their surfaces and different rake angles between each of the samples. Manufacturers claim that the M-Wire Ni-Ti alloy impro-

Table 1. Comparison between the different sections and uses of the files evaluated.

\begin{tabular}{|l|c|c|c|c|c|}
\hline Sections & Initial & $\mathbf{2}$ canals & $\mathbf{4}$ canals & $\mathbf{6}$ canals & $\boldsymbol{p}$ \\
\hline $\mathbf{1}$ & $23.67( \pm 1.77)^{*}$ & $24.79( \pm 4.43)$ & $25.90( \pm 2.3)$ & $27.91( \pm 3.77)^{*}$ & $0.027^{*}$ \\
\hline $\mathbf{2}$ & $24.4( \pm 1.91)^{*}$ & $25.39( \pm 2.29)$ & $26.55( \pm 2.34)$ & $28.61( \pm 4.99)^{*}$ & $0.020^{*}$ \\
\hline $\mathbf{3}$ & $24.95( \pm 2.02)^{*}$ & $25.78( \pm 3.89)$ & $26.99( \pm 2.11)$ & $29.09( \pm 2.85)^{*}$ & $0.007^{*}$ \\
\hline
\end{tabular}

* Statistically significant differences between these groups. 
ves flexibility and fatigue resistance compared to conventional Ni-Ti alloy, which has a high risk of fracture $(17,18)$.

A reciprocal instrument travels a shorter angular distance than a rotary instrument; therefore, it is subject to lower stress values and has higher fatigue resistance $(12,13,19)$, a situation that is corroborated in this study, where of 120 shaped canals, none recorded any separation of the Primary reciprocating file, even when the file was used six consecutive times. Other authors evaluated the deformation and fracture rates of 593 conventional rotary files, reporting $16.02 \%$ fractures, confirming the lower resistance of these instruments to cyclic fatigue (7).

Is important to point out that care need to be be taken when using this system in curve canals and with small diameters as reported by Martin et al. (20), who stated that a reduction in the angle of curvature may produce a lower incidence of fracture with rotary Ni-Ti instruments. Conversely, Kim et al. (21), recommended their use in narrow and calcified canals based on their high resistance to torsion. It is worth mentioning that in addition to root anatomy, other factors contribute to optimal conformation, such as instrument design, instrumentation sequence, file speed, operator experience and use of irrigants $(2,22)$.

Primary single-use files of the WaveOne system proved highly effective for cutting when used in a reciprocal movement. However, the files' effective cutting action was only maintained through the shaping of four vestibular canals of primary maxillary molars, in contrast to those reported by You et al. (13), who studied the behavior of the F2 file of the Protaper system with reciprocal movement in vestibular canals of maxillary and mandibular molars and established their safe use for six canals.

Other researchers that have compared reciprocating systems established that the Reciproc system resisted dynamic and static fatigue cycles more than the WaveOne system and that the probability of half-life was higher for Reciproc than for WaveOne $(23,24)$. Thus, future research should consider extending the study of the wear of files to other mechanized systems.

According to the present in vitro study, the use of Primary files of the WaveOne system can be recommended for the shaping of up to four root canals without the edges losing their effectiveness.

\section{References}

1. Schilder H. Cleaning and shaping the root canal. Dent Clin North Am. 1974;18:269-96.

2. Peters OA. Current challenges and concepts in the preparation of root canal systems: a review. J Endod. 2004;30:559-67.

3. Walia H, Brantley WA, Gerstein H. An initial investigation of the bending and torsional properties of Nitinol root canal files. J Endod. 1988;14:346-51.

4. Ye J, Gao Y. Metallurgical characterization of M-Wire of nickeltitanium shape memory alloy used for endodontic rotary instruments during low-cycle fatigue. J Endod. 2012;38:105-7.

5. Glossen C, Haller RH, Dove SB, del Rio CE. A comparison of root canal preparations using Ni-Ti hand, Ni-Ti engine-driven, and K-Flex endodontic instruments. J Endod. 1995;21:146-51.

6. Schäfer E, Vlassis M. Comparative investigation of two rotary nickel-titanium instruments: ProTaper versus RaCe. Part 2. Cleaning effectiveness and shaping ability in severely curved root canals of extracted teeth. Int Endod J. 2004;37:239-48.

7. Inan U, Gonulol N. Deformation and fracture of Mtwo rotary nickeltitanium instruments after clinical use. J Endod. 2009;35:1396-9.

8. Baek SH, Lee CJ, Versluis A, Kim BM, Lee W, Kim HC. Comparison of torsional stiffness of Nickel-Titanium rotary files with different geometric characteristics. J Endod. 2011;37:1283-6.

9. Johnson E, Lloyd A, Kuttler S, Namerow K. Comparison between a novel nickel-titanium alloy and 508 nitinol on the cyclic fatigue life of ProFile 25/.04 rotary instruments. J Endod. 2008;34:1406-9.

10. Gao Y, Shotton V, Wilkinson K, Phillips G, Johnson WB. Effects of raw material and rotational speed on the cyclic fatigue of ProFile Vortex rotary instruments. J Endod 2010;36:1205-9.

11. Pérez-Higueras JJ, Arias A, de la Macorra JC, Peters OA. Differences in cyclic fatigue resistance between ProTaper Next and ProTaper Universal instruments at different levels. J Endod. 2014;40:1477-81.

12. De-Deus G, Moreira EJ, Lopes HP, Elias CN. Extended cyclic fatigue life of F2 ProTaper instruments used in reciprocating movement. Int Endod J. 2010;43:1063-8.

13. You SY, Bae KS, Baek SH, Kum KY, Shon WJ, Lee W. Lifespan of one nickel-titanium rotary file with reciprocating motion in curved root canals. J Endod. 2010;36:1991-4.

14. Roane JB, Sabalac CL, Duncanson MG Jr. The "balanced force" concept for instrumentation of curves canals. J Endod. 1985;11:20311.

15. Schneider SW. A comparison of canal preparations in straight and curved root canals. Oral Surg Oral Med Oral Pathol. 1971;32:271-5.

16. Anderson ME, Price JW, Parashos P. Fracture resistance of electropolished rotary nickel-titanium endodontic instruments. J Endod. 2007;33:1212-6.

17. Pedullà E, Grande NM, Plotino G, Gambarini G, Rapisarda E. Influence of continuous or reciprocating motion on cyclic fatigue resistance of 4 different nickel-titanium rotary instruments. J Endod. 2013;39:258-61.

18. Sattapan B, Nervo GJ, Palamara JE, Messer HH. Defects in rotary nickel-titanium files after clinical use. J Endod. 2000;26:161-5.

19. Gambarini G, Rubini AG, Al Sudani G, Gergi R, Culla A, De Angelis F, et al. Influence of different angles of reciprocation on the cyclic fatigue of nickel-titanium endodontic instruments. J Endod. 2012;38:1408-11.

20. Martín B, Zelada G, Varela P, Bahillo JG, Magán F, Ahn S, et al. Factors influencing the fracture of nickel-titanium rotary instruments. Int Endod J. 2003;36:262-6.

21. Kim HC, Kwak SW, Cheung GS, Ko DH, Chung SM, Lee W. Cyclic fatigue and torsional resistance of two new nickel-titanium instruments used in reciprocation motion: Reciproc versus WaveOne. J Endod. 2012;38:541-4.

22. Karabucak B, Gatan AJ, Hsiao C, Iqbal MK. A comparison of apical transportation and length control between EndoSequence and Guidance rotary instruments. J Endod. 2010;36:123-5.

23. De-Deus G, Leal Vieira E, Nogueira da Silva EJ, Lopes H, Elias $\mathrm{CN}$, Moreira EJ. Bending resistance and dynamic and static cyclic fatigue life of Reciproc and WaveOne large instruments. J Endod. 2014;40:575-9.

24. Arias A, Perez-Higueras JJ, de la Macorra JC. Differences in cyclic fatigue resistance at apical and coronal levels of Reciproc and WaveOne new files. J Endod. 2012;38:1244-8.

Acknowledgements

The authors want to acknowledge the DIUFRO Project DI16-0048.

\section{Conflict of Interest}

The authors have no conflict of interest related to this article. 